\title{
The emergence of spanking among a representative sample of children under 2 years of age in North Carolina
}

\author{
Adam J. Zolotor ${ }^{*}$, T. Walker Robinson ${ }^{2}$, Desmond K. Runyan ${ }^{3}$, Ronald G. Barr ${ }^{4}$ and Robert A. Murphy ${ }^{5}$ \\ 1 Department of Family Medicine and Injury Prevention Research Center, University of North Carolina, Chapel Hill, NC, USA \\ 2 Department of Pediatrics, Duke University Medical Center, Durham, NC, USA \\ ${ }^{3}$ Robert Wood Johnson Clinical Scholar Program, Departments of Social Medicine and Pediatrics, University of North Carolina, Chapel Hill, NC, USA \\ ${ }_{4}^{4}$ Department of Pediatrics and Developmental Neurosciences and Child Health, Child and Family Research Institute, University of British Columbia, Vancouver, BC, \\ Canada \\ ${ }^{5}$ Center for Child \& Family Health and Department of Psychiatry \& Behavior Sciences, Duke University Medical Center, Durham, NC, USA
}

\section{Edited by:}

Josephine Johns, University of North

Carolina at Chapel Hill, USA

\section{Reviewed by:}

Elizabeth Gershoff, University of Texas at Austin, USA

Christopher Greeley, University of

Texas Health Science Center at

Houston, USA

\section{${ }^{*}$ Correspondence:}

Adam J. Zolotor, Department of Family

Medicine and Injury Prevention

Research Center, University of North

Carolina, CB \#9595, Chapel Hill, NC

27599-7595, USA.

e-mail: ajzolo@med.unc.edu
Spanking is common in the United States but less common in many European countries in which it has been outlawed. Being spanked has been associated with child abuse victimization, poor self-esteem, impaired parent-child relationships, and child and adult mental health, substance abuse, and behavioral consequences. Being spanked as a child has also been shown to increase the likelihood of abusing one's own children or spouse as an adult. Spanking of very young children less than two is almost never recommended even among experts that consider spanking as reasonable in some circumstances. Using a cross-sectional anonymous telephone survey, we describe spanking rates among a representative sample of North Carolina mothers of children less than 2 years old and the association of spanking with demographic characteristics. A substantial proportion of mothers admit to spanking their very young children. The rate of spanking in the last year among all maternal respondents was 30\%. Over $5 \%$ of the mothers of 3-month olds reported spanking. Over $70 \%$ of the mothers of 23-month olds reported spanking. Increased spanking was associated with higher age of the child and lower maternal age. With every month of age, a child had $27 \%$ increased odds of being spanked. Early spanking has been shown to be associated with poor cognitive development in early childhood. Further, early trauma has been shown to have significant effects on the early developing brain. It is therefore critical that health and human services professionals address the risk of corporal punishment as a method of discipline early in the life of the child. The spanking of very young children may be an appropriate locus for policy and legislative debates regarding corporal punishment.

Keywords: spanking, corporal punishment, early childhood, survey research

\section{INTRODUCTION}

There is mounting evidence that corporal punishment is detrimental to the health and development of children, yet recent studies from the USA have reported that $45-95 \%$ of children were spanked in the previous year (Straus and Stewart, 1999; Theodore et al., 2005; Vittrup et al., 2006; Zolotor et al., 2011). Some studies focusing on early childhood have shown similarly high rates for young children with the risk of even more deleterious consequences. Studies over the last decade have described $29-77 \%$ of parents reporting spanking children less than age of 2 years of age (Straus and Stewart, 1999; Wissow, 2001; Regalado et al., 2004; Slade and Wissow, 2004; Socolar et al., 2005, 2007). To date, no studies have measured rates by age in months spanking during this early developmental period, although increasing infant age is clearly associated with increased use of spanking (Combs-Orme and Cain, 2008).

Spanking has numerous deleterious consequences on child health and development. A systematic review of the consequences of spanking which included 88 empirical studies reported that spanking was associated with moral internalization, aggression, delinquent and antisocial behavior, poorer quality of the parent-child relationship, poorer mental health, and an increased likelihood of being a victim of physical abuse. Furthermore, spanking during childhood was associated in later adulthood with aggression, criminal and antisocial behavior, poorer mental health, and adult abuse of one's own child or spouse. The only benefit of corporal punishment identified in this systematic review was improved immediate compliance (Gershoff, 2002).

The age of spanking occurrence may have an impact on the developmental and behavioral consequences of spanking. Numerous studies have shown that earlier abuse and neglect has a greater impact on development than later abuse and neglect (Keiley et al., 2001; Kaplow and Widom, 2007; Kotch et al., 2008). Less is known about the consequences of early spanking relative to later spanking regarding differential developmental consequences. One longitudinal study of discipline at age three found that, among girls, physical discipline was associated with a lower IQ (Smith and Brooks-Gunn, 1997). A subsequent study with a much larger sample and more effective control of confounding variables reported that spanking at 1 year of age was associated with aggressive behavior at 2 years of age and lower developmental scores at three compared to children that were not spanked (Berlin et al., 2009). A recent prospective cohort study reported that spanking at three was associated with increased aggressive behavior at five, 
further reinforcing that the groundwork for adverse developmental and behavioral consequences of spanking may be laid at a young age (Taylor et al., 2010).

Spanking has been associated repeatedly with physical abuse. Child protective service substantiated abuse often results from escalated spanking (Kadushin and Martin, 1981). It is consistently reported that abusive parents are far more likely to spank then nonabusive parents (Gershoff, 2002). A recent study reported that spanking frequency and intensity (use of an object) was associated with increasing probability of self-reported abuse (Zolotor et al., 2008).

Being spanked as a child has been shown to be associated with later abuse of one's own child or spouse in several studies. The study of intergenerational transmission of violence is particularly challenging because of the long time lag between a child's own spanking or other assault and the number and complexity of intervening variables. Seven cross-sectional studies on the effects of spanking report a consistent relationship between being spanked and later abuse of one's own child and spouse (Straus and Gelles, 1990; Gershoff, 2002; Straus and Donnelly, 2005). This association may be the result of other consequences of spanking (such as increased aggression) or due to social learning theory in which children who are spanked themselves "learn" to use violence for resolution of conflict at a young age.

Given the convergent evidence that early abuse and neglect may be more harmful than later abuse and neglect and the similar developmental and behavioral consequences of spanking, we felt that a more detailed understanding of when spanking begins to occur in early childhood would help to better understand these relationships. Further, if it is desirable to curb spanking and/or give parents alternate tools for discipline, it is important to understand when such behaviors begin to occur. We therefore conducted a cross-sectional survey of mothers of children less than approximately 2 years of age in North Carolina (NC) to examine the age-dependent trajectory of rates of spanking. Mothers were asked to report their own disciplinary practices as well as those of spouses or partners involved in raising the child. For the purposes of this study, spanking is defined as being "hit on the buttocks with the hand only." Our primary goal was to describe the pattern of adoption of spanking by mothers as a disciplinary practice in very young children. A secondary goal was to determine whether rates of early spanking were significantly different among mothers with differing demographic backgrounds.

\section{MATERIALS AND METHODS STUDY DESIGN AND SAMPLING}

An anonymous telephone survey on child rearing was administered to a stratified probability sample of North Carolina mothers. The target population consisted of all live births to English or Spanish-speaking mothers born in North Carolina between October 1, 2005 and July 31, 2007. The anticipated sample size was 3450 subjects. Subjects were selected using a random selection procedure from birth certificates. A total of 38,334 live birth certificates were selected. Strata were created based on mother's education, age, and tobacco or alcohol as indicated on the birth certificate. Proportional sampling was done at random from each stratum. Each mother's name and address from a birth certificate was provided to a survey research firm (GENESYS Sampling Systems, Fort Wayne, Pennsylvania) which was back-matched on publicly available telephone numbers for calling.
To be eligible to participate in the study, a selected birth certificate had to be matched with a current telephone number of a North Carolina household. A child born between October 1, 2005 and July 21, 2007 needed to reside in the household. A referent child was selected at random. The mother or female guardian of the referent child had to speak English or Spanish and the interview was conducted in her preferred language. There was no attempt to verify birth certificate matching to minimize the threat of breach of confidentiality. Because of the time lag for birth certificate completion, matching, and entry into the field, we expected to have few subjects with infants less than 3 months of age. Further, we attempted to include mothers of children through 24 months of age in the sample by selection of birth certificates, though considered mothers of children through 30 months to meet eligibility criteria.

The survey was conducted from October 1, 2007 to April 7, 2008 at the Survey Research Unit of the University of North Carolina. Blaise 4.6 (Statistics, Netherlands), a computer-assisted telephone interview software package by Statistics Netherlands, was used when administering the survey. A minimum of 12 call-back attempts were on a rotating schedule. Calls could be scheduled at the preference of the subject. Interviewers were trained according to standard procedures at the Survey Research Unit and the lead author about the contents and purpose of this survey. The survey was translated into Spanish and independently back-translated. All respondents were given phone numbers for parenting resources as part of a routine "debriefing." After initially connecting with a potential respondent and prior to administering the survey, the phone number and identity of the respondent was purged from the computer system. The respondent was therefore not traceable, thus allowing for a truly anonymous survey. It was approved by the University of North Carolina School of Medicine Institutional Review Board.

\section{MEASURES}

The survey was designed to describe parenting behaviors, disciplinary practices, and family and community characteristics. The parenting behaviors were assessed using questions selected from the Parent Child Conflict Tactics Scales (PCCTS; Straus et al., 1998). The PCCTS asks parents about a variety of positive and negative discipline techniques, including positive and negative reinforcement, corporal punishment, and potentially abusive behaviors. In addition, supplemental questions for neglect were asked from the PCCTS. Questions from the PCCTS were asked of both the responding mother's behaviors toward the index child and the behavior of her partner toward the index child (two separate questions). Respondents are asked to indicate how many times they have used each practice in the last year, varying from none to more than 20 times. Then, if the answer is "not in the past year," they are asked if they have ever used this practice. Additional questions include family composition, employment, and ethnicity so that the data could be weighted to provide population estimates for the state. The use of anonymous surveys to assess potentially abusive caregiver behaviors utilizes the work of Straus which shows that caregivers are willing to report harsh and socially disapproved of forms of discipline (Straus and Gelles, 1990). The PCCTS has been widely used to assess parenting practices (Tajima, 2000; Theodore et al., 2005; Zolotor et al., 2008 \#48) 


\section{STATISTICAL ANALYSIS}

Sample weights addresses the disproportionality in the sample arising from the sampling process. Variables included in the weighting process included mother's education, mother's age, tobacco or alcohol use during pregnancy (stratification variables), and marital status, race/ethnicity of mother, urbanization of county, and father's education. These weighting procedures allow the survey results to best approximate the true frequencies of behaviors for the target population in North Carolina.

Spanking frequencies were determined for each month-long age category, for a total of 25 categories between 3 and 25 months. These proportions are summarized using a simple histogram. Mothers were dichotomized as spankers or non-spankers of the index child. Among self-reported spankers, we assessed the number of times each mother reported spanking their child in the previous year. Spankers and non-spankers were then compared according to selected maternal, child, and demographic characteristics one at a time. These included maternal age, marital status, educational level, ethnicity, household income, as well as age and sex of the child. Survey-weighted bivariate logistic regression analyses were conducted for each independent variable. Survey-weighted multiple logistic regression was then used to examine the potential associations between spanking and these maternal demographic characteristics in full multivariate models. Models were reduced to maximize statistical power by eliminating demographic variables that were related at a statistical level of significance greater than 0.10. Analysis was conducted using Stata version 10.0 (Stata Corp., College Station, TX, USA).

\section{RESPONSE RATE}

A large number of birth certificates $(38,334)$ were back-matched for telephone numbers due to anticipated changes in address, phone number, and unlisted numbers. Forty-nine percent of names and addresses $(18,789)$ were matched to a telephone number. Of these, 12,828 were entered into calling, 2884 subjects completed the interview, and 62 subjects partially completed the interview. This resulted in a total sample of 2946 mothers. There were 1248 respondents determined to be eligible but who did not complete a sufficient part of the interview for inclusion, 3024 numbers of unknown eligibility, and 5610 numbers found to be ineligible.

Response rate was determined using the American Association for Public Opinion Research Standard Definitions (2008). Unknown numbers were adjusted for eligibility status and inclusion in the denominator by determining the proportion which, if contacted, should have been eligible. This is a conservative approach to the determination of response rates known as response rate option 4 (American Association of Public Opinion Research, 2008). This approach yielded a conservative response rate of $53.6 \%$.

\section{RESULTS}

\section{SUBJECT CHARACTERISTICS}

Table 1 reports both unweighted and weighted maternal and family characteristics for the 2946 maternal respondents, while Table 2 separates the maternal respondents into those who had and had not spanked the index child. The majority of mothers surveyed were married, middle to high income, and of Caucasian ethnicity. Nearly $(48 \%)$ half of mothers surveyed were college graduates. More than
Table 1 | Description of survey respondents $(N=2946)$.

\begin{tabular}{lcc}
\hline Characteristic & Unweighted percent & Weighted percent \\
\hline AGE OF CHILD, MONTHS & & \\
$3-7$ & 20.2 & 19.0 \\
$8-12$ & 25.0 & 25.8 \\
$13-17$ & 21.9 & 22.0 \\
18-22 & 21.9 & 21.0 \\
23-27 & 11.1 & 12.2 \\
SEX OF CHILD & & \\
Male & 52.0 & 51.8 \\
Female & 48.0 & 48.3 \\
MATERNAL AGE & & \\
14-20 & 7.0 & 12.5 \\
21-35 & 76.7 & 75.3 \\
36-49 & 16.4 & 12.3 \\
MARITAL STATUS & & \\
Married & 81.6 & 60.6 \\
Single & 18.4 & 39.4 \\
EDUCATION STATUS & & \\
Less than high school & 10.9 & 48.3 \\
HS grad/some college & 40.7 & 35.0 \\
College graduate or higher & 48.4 & \\
\hline ETHICIT/RACE (MUTUALY & & \\
\hline
\end{tabular}

ETHNICITY/RACE (MUTUALLY EXCLUSIVE CATEGORIES)

\begin{tabular}{lrr} 
African American/Black & 12.3 & 19.9 \\
Asian/Pacific Islander & 2.2 & 1.5 \\
Hispanic & 10.5 & 15.2 \\
White/Caucasian & 74.2 & 62.4 \\
Native American/Indian & 0.7 & 0.9 \\
Other & 0.1 & 0.6 \\
ANNUAL HOUSEHOLD INCOME & \\
Less than $\$ 40,001$ & 29.0 & 42.1 \\
40,001-80,000 & 35.4 & 31.6 \\
$80,001+$ & 35.6 & 26.3 \\
\hline
\end{tabular}

$99 \%$ of respondents were the biological mother of the index child. The index children were between 3 and 27 months of age. There were roughly equal numbers of boys and girls.

\section{SPANKING RATE}

Of the 2946 mothers surveyed, nearly $1 / 3$ (29.9\%) reported spanking their child in the past year. This figure is very similar to the $30.0 \%$ prevalence of spanking of children less than 2 years old in a 2002 survey of North Carolina and South Carolina mothers ( $n=115$ of 384 mothers of children less than 2; Theodore et al., 2005). Frequency of spanking among spankers in the past year is graphically represented in Figure 1. Notably, 10.8\% of those who had spanked their index child at least once responded that they had spanked their child more than 20 times in the past year.

\section{MATERNAL AND FAMILY CHARACTERISTICS PREDICTING SPANKING}

The relationships between respondents of differing demographic characteristics and the use of spanking as a disciplinary method were examined using survey-weighted multivariate logistic regression models. Three maternal characteristics predicted reported 
Table 2 |Weighted comparison of spankers and non-spankers ( $N=2946)$.

\begin{tabular}{|c|c|c|c|}
\hline \multirow[b]{2}{*}{ Characteristic } & \multicolumn{2}{|c|}{ Weighted percent } & \multirow{2}{*}{$\begin{array}{l}\text { Number } \\
\text { All respondents }\end{array}$} \\
\hline & Spankers & Non-spankers & \\
\hline \multicolumn{4}{|c|}{ AGE OF CHILD, MONTHS } \\
\hline $3-7$ & 1.4 & 98.6 & 577 \\
\hline $8-12$ & 8.6 & 91.4 & 715 \\
\hline $13-17$ & 32.6 & 67.4 & 628 \\
\hline $18-22$ & 57.1 & 42.9 & 626 \\
\hline $23-27$ & 64.0 & 36.0 & 317 \\
\hline \multicolumn{4}{|l|}{ SEX OF CHILD } \\
\hline Male & 31.9 & 66.6 & 1533 \\
\hline Female & 27.7 & 72.3 & 1413 \\
\hline \multicolumn{4}{|l|}{ MATERNAL AGE } \\
\hline $14-20$ & 33.4 & 66.6 & 205 \\
\hline $21-35$ & 30.6 & 69.4 & 2258 \\
\hline $36-49$ & 24.7 & 75.3 & 483 \\
\hline \multicolumn{4}{|l|}{ MARITAL STATUS } \\
\hline Married & 30.1 & 69.9 & 2405 \\
\hline Single & 29.5 & 70.5 & 541 \\
\hline \multicolumn{4}{|l|}{ EDUCATION STATUS } \\
\hline Less than high school & 26.7 & 73.3 & 322 \\
\hline HS grad/some college & 29.3 & 70.7 & 1199 \\
\hline College graduate or higher & 32.3 & 67.7 & 1425 \\
\hline \multicolumn{4}{|l|}{ ETHNICITY/RACE } \\
\hline African American/Black & 26.2 & 73.8 & 362 \\
\hline Asian/Pacific Islander & 28.9 & 71.1 & 64 \\
\hline Hispanic & 21.8 & 78.2 & 308 \\
\hline White/Caucasian & 32.8 & 67.2 & 2187 \\
\hline Native American/Indian & 40.7 & 59.4 & 21 \\
\hline Other & 29.9 & 70.1 & 4 \\
\hline \multicolumn{4}{|c|}{ ANNUAL HOUSEHOLD INCOME } \\
\hline Less than $\$ 40,001$ & 27.8 & 72.2 & 800 \\
\hline $40,001-80,000$ & 33.4 & 66.6 & 977 \\
\hline $80,001+$ & 29.2 & 70.8 & 984 \\
\hline
\end{tabular}

spanking in our final multivariable logistic regression model (see Table 3). Spanking was inversely associated with maternal age. Increasing maternal age was associated with a decrease in the odds of spanking. For each year of age, mothers were at $2 \%$ lower odds of reporting spanking $(p=0.001)$. There was a significant relationship between spanking occurrence and maternal ethnicity. Mothers of Asian, Native American, and other ethnic groups participated in the survey in low numbers. Estimates of these associations with spanking are imprecise. Hispanic mothers had one-fourth the odds of spanking compared to white mothers $(\mathrm{OR}=0.25 ; p<0.001)$ and black mothers were also less likely to spank $(\mathrm{OR}=0.60, p=0.01)$. Finally, household income was unrelated to spanking occurrence as was reported maternal education.

As expected, there was a significant relationship between increased child age and maternal spanking practices. Mothers had 1.27 times the odds of spanking their child with each increasing month of the child's life $(p<0.001)$. Mothers of boys were at higher odds of spanking than mothers of girls (OR 1.27, $p=0.05$ ). Figure 2 shows a simple histogram of spanking by child age in months. This figure demonstrates the age at which a majority of mothers report spanking occurs between 18 and 19 months of age.

\section{DISCUSSION}

Among mothers in North Carolina, spanking of children under the age of two is quite common. Almost one-third of mothers (30.0\%) of young children spanked their child in the past year, some more than 20 times. This rate closely resembles that reported by Slade and Wissow (2004; 38.7\% in a nationally representative sample), Socolar et al. (2005; 29\% among a NC sample), and a similar 2002 study of North and South Carolina maternal discipline practices in children $0-2$ years of age ( $30.0 \%$ among a small sample; Theodore et al., 2005). Unlike these three earlier studies, however, our survey enabled a month-by-month examination of spanking trends in children aged 3-24 months. Multivariate logistic regression showed significant differences in rates of spanking differences among mothers of different ages and ethnicities as well as children of different ages and sex.

While much of the spanking literature has assessed the relationship between parental demographics and spanking across the entire pediatric age spectrum, this study focuses on very young children. Our results support earlier evidence that older mothers are less likely to spank (Smith and Brooks-Gunn, 1997; Day et al., 1998; Eamon, 2001; Wissow, 2001; Regalado et al., 2004). Older mothers may have a better understanding of child development and more experience with children. Contrary to much of the literature associating African American ethnicity with higher spanking prevalence (Smith and Brooks-Gunn, 1997; Day et al., 1998; Socolar et al., 1999; Straus and Stewart, 1999; Pinderhughes et al., 2000; Wissow, 2001; Horn et al., 2004; Regalado et al., 2004; Barkin et al., 2007), we found African American mothers reported spanking less often than white mothers. Black mothers may be less likely to spank very young children, but this relationship may not persist as children age. Hispanic mothers also reported spanking less often than white mothers.

Our analysis of the relationship of household income with spanking yielded no significant association. Previous reports of this relationship have been equivocal. Seven studies have found a direct relationship between decreased income and increased spanking practices (Giles-Sims et al., 1995; Smith and Brooks-Gunn, 1997; Socolar et al., 1999; Straus and Stewart, 1999; Pinderhughes et al., 2000; Wissow, 2001; Regalado et al., 2004), four studies found no relationship between income and spanking prevalence (BuntainRicklefs et al., 1994; Day et al., 1998; Horn et al., 2004; Grogan-Kaylor and Otis, 2007), and one study reported equivocal results (Socolar et al., 2005). In our study, mothers at the lowest end of the economic spectrum $(<\$ 40,000$ per year) were not more likely to spank than mothers in households earning more than $\$ 80,000$ per year, though households earning in a mid-range income of \$40,000-80,000 per year reported spanking at higher rates, but this was not statistically significant. It may be that spanking in the US today is no longer associated with economic status, or that our crude measure of economic status failed to capture these differences. 


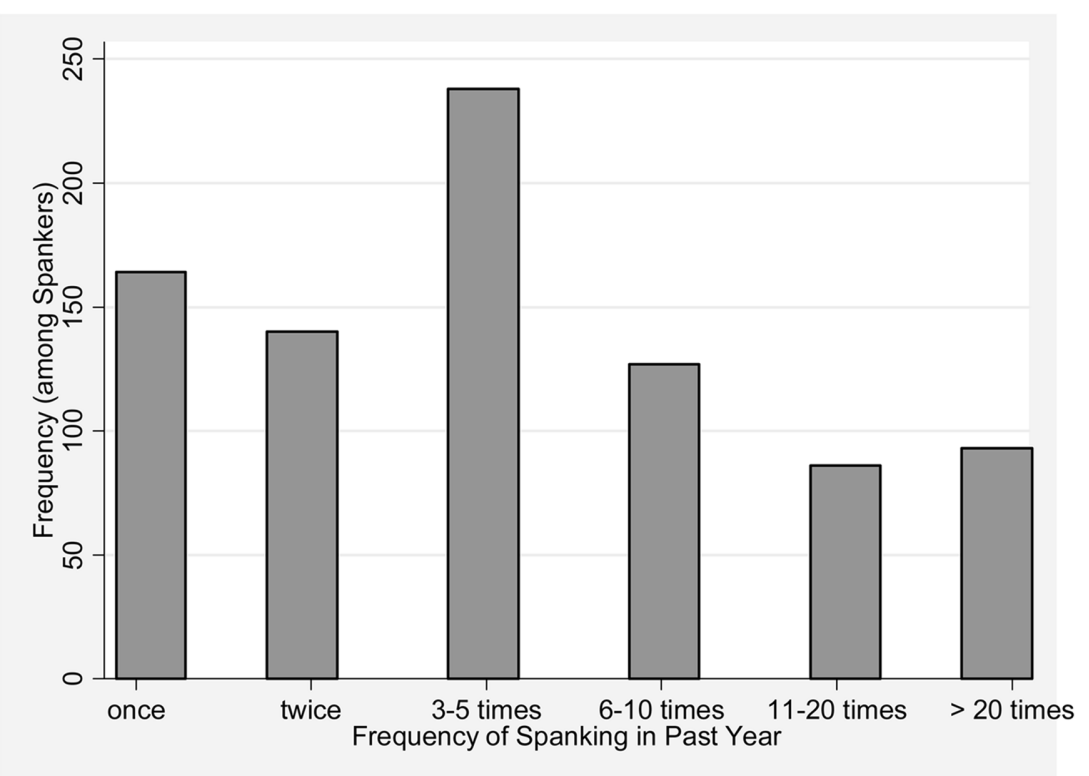

FIGURE 1 | Spanking frequency among spankers ( $N=875)$. Note: This figure does not include the 2027 mothers (70\%) who reported not spanking in the past year.

Table 3 | Logistic regression models of spanking behavior on maternal characteristics $(N=2790)$.

Independent variables
Models

\begin{tabular}{|c|c|c|c|c|c|}
\hline \multicolumn{2}{|c|}{ Bivariate } & \multicolumn{2}{|c|}{ Full multivariate ${ }^{1}$} & \multicolumn{2}{|c|}{ Final multivariate ${ }^{2}$} \\
\hline Odds ratio & $p$-value & Odds ratio & $p$-value & Odds ratio & $p$-value \\
\hline 1.24 & $<0.001 * * *$ & 1.23 & $<0.001^{* * *}$ & 1.27 & $<0.001 * * *$ \\
\hline 1.22 & $0.04^{*}$ & 1.27 & 0.06 & 1.27 & $0.05^{*}$ \\
\hline 0.98 & $0.03 *$ & 0.96 & $0.001 * * *$ & 0.95 & $<0.001 * * *$ \\
\hline 0.97 & 0.79 & 0.80 & 0.23 & - & - \\
\hline 1.00 & - & 1.00 & - & 1.00 & - \\
\hline 1.14 & $0.04^{*}$ & 1.33 & 0.27 & 1.32 & 0.28 \\
\hline 1.31 & 0.09 & 1.79 & $0.05^{*}$ & 1.65 & 0.06 \\
\hline 0.73 & $0.03^{*}$ & 0.57 & $0.01 * *$ & 0.60 & $0.01 * *$ \\
\hline 0.83 & 0.59 & 0.78 & 0.64 & 0.75 & 0.56 \\
\hline 0.57 & $0.02 *$ & 0.25 & $<0.001^{* * *}$ & 0.25 & $<0.001 * * *$ \\
\hline 1.00 & - & 1.00 & - & 1.00 & - \\
\hline 1.40 & 0.66 & 1.25 & 0.65 & 1.29 & 0.59 \\
\hline 1.99 & 0.57 & 1.66 & 0.56 & 1.46 & 0.67 \\
\hline 1.00 & - & 1.00 & - & - & - \\
\hline 1.29 & $0.03^{*}$ & 0.80 & 0.19 & - & - \\
\hline 1.00 & 0.48 & 1.09 & 0.64 & - & - \\
\hline
\end{tabular}

${ }^{*} p<0.05$.

${ }^{* *} p<0.01$.

${ }^{* *} p<0.001$.

${ }^{1}$ Full model from survey-weighted logistic regression controlling for all other demographic variables in table.

${ }^{2}$ Reduced model maintains all demographic variables with p-value $>0.1$ (in the case of categorical variables, all variables maintained in model). 


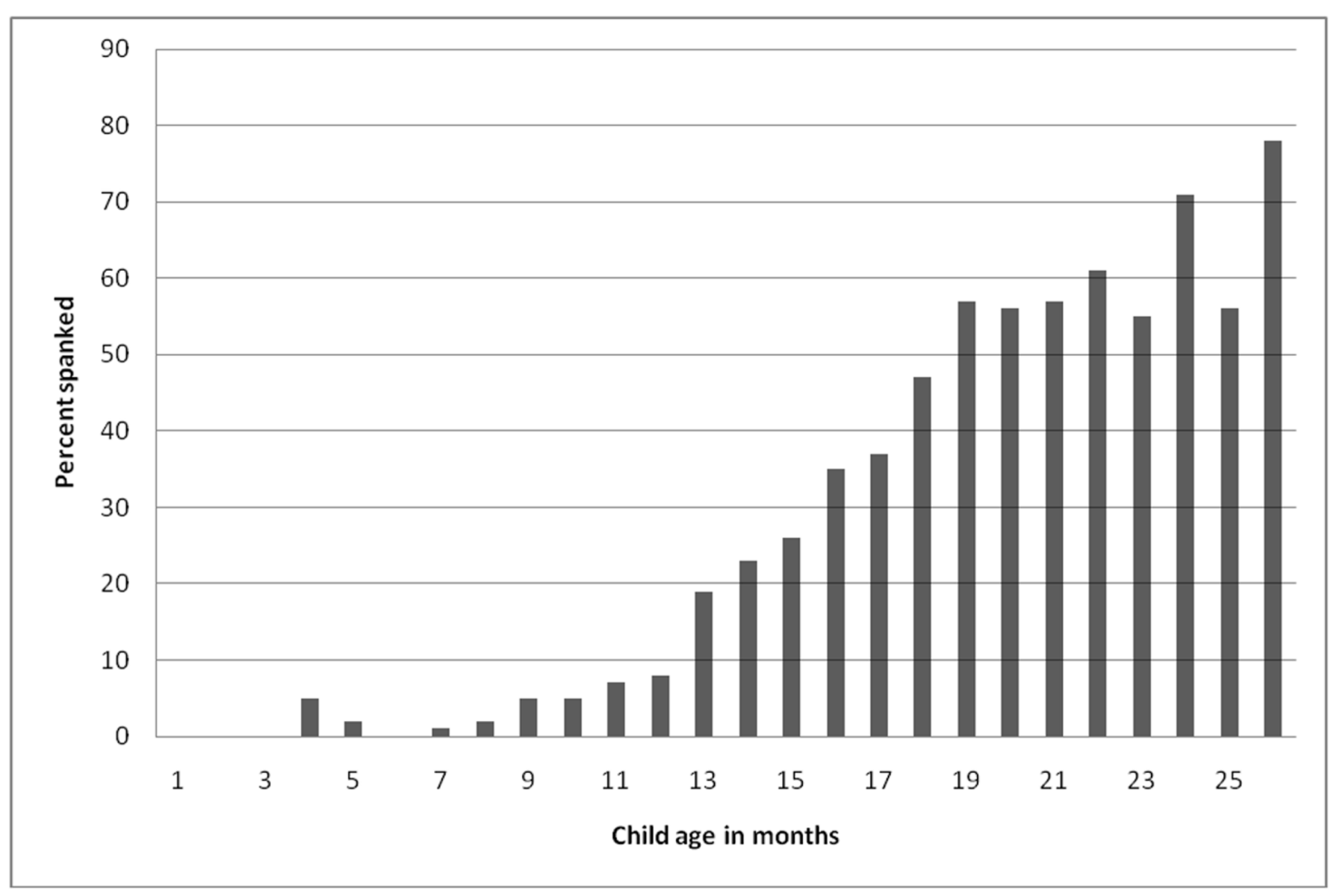

FIGURE 2 | Percent mother reported spanking by child age in months (weighted data).

Despite past studies associating differential spanking prevalence with maternal marital status (Giles-Sims et al., 1995; Smith and Brooks-Gunn, 1997; Regalado et al., 2004) and educational attainment (Smith and Brooks-Gunn, 1997; Day et al., 1998; Socolar et al., 1999; Eamon, 2001; Barkin et al., 2007), neither characteristic significantly predicted spanking in our study. Our study found, as have several others, (Giles-Sims et al., 1995; Smith and Brooks-Gunn, 1997; Day et al., 1998; Pinderhughes et al., 2000; Wissow, 2001), that the sex of the child predicted spanking prevalence with boys being more likely to be spanked. The lack of association between maternal education has been previously reported in another large nationally representative study (Grogan-Kaylor and Otis, 2007). As expected, most prevalence studies have shown an inverse relationship between child age and spanking prevalence throughout the early childhood years (Buntain-Ricklefs et al., 1994; Day et al., 1998; Regalado et al., 2004), a finding also supported by our study.

This study suggests that the 1996 American Academy of Pediatrics (AAP) panel conclusions (Bauman and Friedman, 1998) that children under the age of 2 should not be spanked and the 1998 AAP recommendation (Stein and Perrin, 1998) against spanking as a primary disciplinary practice, particularly in children under 18 months of age, are not being followed consistently. In Bright Futures, the AAP's Guidelines for Health Supervision of Infants, Children, and Adolescents (American Academy of Pediatrics. Committee on Psychosocial Aspects of Child and Family Health., 2002), discipline is first mentioned as a component of anticipatory guidance during the 9-month visit, at which point health care providers are advised to discuss parenting expectations, consistency, behavior management, and cultural beliefs about child-rearing. In our study, 8\% of mothers of children aged 3-9 months of age already report having spanked their child by this time. As for spanking practices in older children (9- to 24-month olds), child health care providers may not address issues of child discipline in the periodic well-child visits, although it also may be that their advice is not being heeded as other cultural forces regarding spanking may be operating. Our results indicate that pediatric health care professionals should begin discussing discipline strategies with parents as early as the 2-or 4-month visit. Each visit thereafter should seek to assess the success of current discipline strategies, reinforcing practices other than spanking. Several intensive home visiting programs have been shown to reduce spanking or improve positive discipline. Healthy Families America and Healthy Start have shown a reduction in harsh parenting (Duggan et al., 2004; DuMont et al., 2008). The Nurse Family Partnership has shown improved maternal responsivity and use of positive discipline (Olds et al., 2002). Incredible Years has reported less harsh discipline (verbal and physical), less physical punishment, more positive discipline, and improved child behavior (Letarte et al., 2010). A particular therapeutic model, Parent Child Interaction Therapy has been shown to improve positive parental responses to appropriate behavior (Thomas and Zimmer-Gembeck, 2011). Public health interventions such as media coverage and legislative efforts may also reduce the early spanking practices of the public.

Further research continues to be needed in the area of child discipline. Studies of association between early spanking to later outcomes such as aggression or antisocial behavior are methodologically 
difficult. Efforts to show causal connections between spanking and later negative outcomes need to be undertaken while controlling for other discipline styles and practices. The study of spanking and public discourse about spanking policy and practice tend to be polarizing and based the importance of values such as parents' rights, children's rights, autonomy, and justice. These are important values to consider in the application of spanking research to public discourse. However, with limited exceptions, most parenting experts that advocate for corporal punishment do not recommend the use of this type of discipline for children less than two. More empiric evidence on the consequences of spanking, and especially early spanking, may sway parents, practitioners, and policy makers. By learning alternatives to spanking parents may come to understand that children need not learn through fear, and that the hard and important lessons of childhood can be taught in other ways.

There were a number of limitations to this study. First, this is a survey of mothers in the state of North Carolina and may not, therefore, be representative of mothers across the USA. Earlier national studies noted higher rates of spanking in the southeastern USA (Giles-Sims et al., 1995; Straus and Stewart, 1999); therefore rates may be lower in other regions. However, regional studies that include the deep South versus the Southeast show that North Carolina rates of spanking are similar to those of the southeast and the whole United States and less similar to those of the South which include the deep South (Zolotor et al., 2011). Second, while respondents described their spouse or partner's discipline practices, we did not specifically ask spouses or partners about such practices. Third, our phone survey included very few cell phone users, potentially limiting the generalizability of our conclusions to cell phone only users. Finally, self-reported disciplinary practices may be underestimations of actual prevalence due to the potential social stigma, even in an anonymous survey, against reporting the use of parental corporal punishment to an unknown surveyor.

\section{REFERENCES}

American Academy of Pediatrics. Committee on Psychosocial Aspects of Child and Family Health. (2002). Guidelines for Health Supervision III, 3rd Edn. Elk Grove Village, IL: American Academy of Pediatrics.

American Association of Public Opinion Research. (2008). Standard Definitions: Final Dispositions of Case Codes and Outcome Rates for Surveys. Lenexa, KS: American Association of Public Opinion Research.

Barkin, S., Scheindlin, B., Ip, E. H., Richardson, I., and Finch, S. (2007). Determinants of parental discipline practices: a national sample from primary care practices. Clin. Pediatr. (Phila.) 46, 64-69.

Bauman, L. J., and Friedman, S. B. (1998). Corporal punishment. Pediatr. Clin. North Am. 45, 403-414.

Berlin, L. J., Ispa, J. M., Fine, M. A., Malone, P. S., Brooks-Gunn, J., Brady-Smith, C., Ayoub, C., and Bai, Y. (2009). Correlates and

The AAP states unequivocally that children under two should not be spanked. Notwithstanding this position, almost one-third of mothers in our survey reported spanking their infant on the buttocks by their second birthday. Not all mothers, however, are equally likely to spank their infant. This study suggests that younger maternal age, non-Hispanic ethnicity, and middle household incomes are associated with a higher likelihood of spanking before the age of 2. Pediatric health care professionals, public health and child development workers should assist parents of very young children in developing a discipline skill set including positive and negative reinforcement without physical punishment as well as setting appropriate behavioral expectations for such children. The goal of such interventions is not to ostracize mothers who seem more likely to spank their infants; rather, the goal is to provide support, offer alternatives, and ultimately prevent disciplinary practices that in some cases may escalate to child abuse. Further, the spanking of young children may be an appropriate locus for starting policy and legislative discussions around a parents "right" to spank, given the near universal professional and scientific opinion about the negative effects of spanking on such young children.

\section{ACKNOWLEDGEMENTS}

This study was supported by the Centers for Disease Control and Prevention grant number 1 U49 CE001275-01. The authors wish to thank Dr. Terrill Bravender, MD, MPH, of Nationwide Children's Hospital, Columbus, OH, USA; Dr. Margaret Gourlay, MD, MPH, of UNC Department of Family Medicine; Dr. Phyllis Fleming, Ph.D., of UNC Center for Health Promotion and Disease Prevention; Dr. Michael Foster, Ph.D., of UNC School of Public Health; and Dr. Catherine Zimmer, Ph.D, of UNC's Odum Institute for Research in Social Science for assistance with the analysis and preparation of the manuscript.

DuMont, K., Mitchell-Herzfeld, S. Greene, R., Lee, E. Lowenfels, A. Rodrigues, M., and Dorabawila, V. (2008). Healthy Families New York (HFNY) randomized trial: effects on early child abuse and neglect. Child Abuse Negl. 32, 295-315.

Eamon, M. K. (2001). Antecedents and socioemotional consequences of physical punishment on children in two-parent families. Child Abuse Negl. 25, 787-802.

Gershoff, E. T. (2002). Corporal punishment by parents and associated child behaviors and experiences: a meta-analytic and theoretical review. Psychol. Bull. 128, 539-579.

Giles-Sims, J., Straus, M. A., and Sugarman, D. B. (1995). Child, maternal, and family characteristics associated with spanking. Fam. Relat. 44, 170-176.

Grogan-Kaylor, A., and Otis, M. (2007). The predictors of parental use of corporal punishment. Fam. Relat. 56 , 80-91.
Horn, I. B., Cheng, T. L., and Joseph, J. (2004). Discipline in the African American community: the impact of socioeconomic status on beliefs and practices. Pediatrics 113, 1236-1241.

Kadushin, A., and Martin, J. A. (1981). Child Abuse: An Interactional Event. New York, NY: Columbia Univeristy Press.

Kaplow, J. B., and Widom, C. S. (2007). Age of onset of child maltreatment predicts long-term mental health outcomes. J. Abnorm. Psychol. 116, 176-187.

Keiley, M. K., Howe, T. R., Dodge, K. A., Bates, J. E., and Pettit, G. S. (2001). The timing of child physial maltreatment: a cross-domain gwoth analysis of impact on adolescent externalizing and internalizing symptoms. Dev. Psychopathol. 13, 8911-8912.

Kotch, J. B., Lewis, T., Hussey, J. M., English,D., Thompson, R., Litrownik, A. J., Runyan, D. K., Bangdiwala, S. I., Margolis, B., and Dubowitz, H. (2008). Importance of early neglect 
for childhood aggression. Pediatrics $121,725-731$.

Letarte, M. J., Normandeau, S., and Allard, J. (2010). Effectiveness of a parent training program "Incredible Years" in a child protection service. Child Abuse Negl. 34, 253-261.

Olds, D. L., Robinson, J., O’Brien, R., Luckey, D. W., Pettitt, L. M., Henderson, C. R., Ng, R. K., Sheff, K. L., Korfmacher, J., Hiatt, S., and Talmi, A. (2002). Home visiting by paraprofessionals and nurses: a randomized, controlled trial. Pediatrics $110,486-496$.

Pinderhughes, E. E., Dodge, K. A., Bates, J. E., Pettit, G. S., and Zelli, A. (2000). Discipline responses: influences of parents' socioeconomic status, ethnicity, beliefs about parenting, stress, and cognitive-emotional processes. J. Fam. Psychol. 14, 380-400.

Regalado, M., Sareen, H., Inkelas, M., Wissow, L. S., and Halfon, N. (2004). Parents' discipline of young children: results from the National Survey of Early Childhood Health. Pediatrics 113(Suppl.), 1952-1958.

Slade, E. P., and Wissow, L. S. (2004). Spanking in early childhood and later behavior problems: a prospective study of infants and young toddlers. Pediatrics 113, 1321-1330.

Smith, J. R., and Brooks-Gunn, J. (1997). Correlates and consequences of harsh discipline for young children. Arch. Pediatr. Adolesc. Med. 151, 777-786.

Socolar, R. R., Savage, E., and Evans, H. (2007). A longitudinal study of parental discipline of young children. South. Med. J. 100, 472-477.

Socolar, R. R., Savage, E., Keyes-Elstein, L., and Evans, H. (2005). Factors that affect parental disciplinary practices of children aged 12 to 19 months. South. Med. J. 98, 1181-1191.

Socolar, R. R., Winsor, J., Hunter, W. M., Catellier, D., and Kotch, J. B. (1999). Maternal disciplinary practices in an at-risk population. Arch. Pediatr. Adolesc. Med. 153, 927-934.

Stein, M. T., and Perrin, E. L. (1998). Guidance for effective discipline. American Academy of Pediatrics. Committee on Psychosocial Aspects of Child and Family Health. Pediatrics 101(Pt 1), 723-728.

Straus, M. A., and Donnelly, D. A. (2005). Beating the DevilOut of Them: Corporal Punishment in American Families and its Effects on Children. New Brunswick, NJ: Transaction Publishers.

Straus, M. A., and Gelles, R. J. (1990). Physical Violence in American Families: Risk Factors and Adaptations to Violence in 8,145 Families. New Brunswick, NJ: Transaction Publishers.

Straus, M. A., Hamby, S. L., Finkelhor, D., Moore, D. W., and Runyan, D. (1998). Identification of child maltreatment with the Parent-Child Conflict Tactics Scales: development and psychometric data for a national sample of American parents. Child Abuse Negl. 22, 249-270.

Straus, M. A., and Stewart, J. H. (1999). Corporal punishment by American parents: national data on prevalence, chronicity, severity, and duration, in relation to child and family characteristics. Clin. Child Fam. Psychol. Rev. 2, 55-70.

Tajima, E. A. (2000). The relative importance of wife abuse as a risk factor for violence against children. Child Abuse Negl. 24, 1383-1398.

Taylor, C. A., Manganello, J. A., Lee, S. J., and Rice, J. C. (2010). Mothers' spanking of 3-year-old children and subsequent risk of children's aggressive behavior. Pediatrics 125(5), e1057-1065.

Theodore, A. D., Chang, J. J., Runyan, D. K., Hunter, W. M., Bangdiwala, S. I., and Agans, R. (2005). Epidemiologic features of the physical and sexual maltreatment of children in the Carolinas. Pediatrics 115, e331-e337.

Thomas, R., and Zimmer-Gembeck, M. J. (2011). Accumulating evidence for parent-child interaction therapy in the prevention of child maltreatment. Child Dev. 82, 177-192.

Vittrup, B., Holden, G. W., and Buck, J. (2006). Attitudes predict the use of physical punishment: a prospective study of the emergence of disciplinary practices. Pediatrics 117, 2055-2064.

Wissow, L. S. (2001). Ethnicity, income, and parenting contexts of physical punishment in a national sample of families with young children. Child Maltreat. 6, 118-129.

Zolotor, A. J., Theodore, A. D., Chang, J. J., Berkoff, M. C., and Runyan, D. K. (2008). Speak softly-and forget the stick. Corporal punishment and child physical abuse. Am. J. Prev. Med. 35, 364-369.

Zolotor, A. J., Theodore, A. D., Runyan, D. K., Chang, J. J., and Laskey, A. L. (2011). Corporal punishment and physical abuse: population-based trends for three-to-11-year-old children in the United States. Child Abuse Rev. 20, 57-66.

Conflict of Interest Statement: The authors declare that the research was conducted in the absence of any commercial or financial relationships that could be construed as a potential conflict of interest.

Received: 21 February 2011; accepted: 09 June 2011; published online: 24 June 2011.

Citation: Zolotor AJ, Robinson TW, Runyan DK, Barr RG and Murphy RA (2011) The emergence of spanking among a representative sample of children under 2 years of age in North Carolina. Front. Psychiatry 2:36. doi: 10.3389/ fpsyt.2011.00036

This article was submitted to Frontiers in Child and Neurodevelopmental Psychiatry, a specialty of Frontiers in Psychiatry. Copyright (c) 2011 Zolotor, Robinson, Runyan, Barrand Murphy. This is an openaccess article subject to a non-exclusive license between the authors and Frontiers Media SA, which permits use, distribution and reproduction in other forums, provided the original authors and source are credited and other Frontiers conditions are complied with. 